\title{
A psychometric evaluation of the Diabetes Symptom Checklist-Revised (DSC-R) cognitive distress, fatigue, hyperglycemia, and hypoglycemia subscales in patients with type I and type 2 diabetes
}

This article was published in the following Dove Press journal: Diabetes, Metabolic Syndrome and Obesity:Targets and Therapy 5 March 2010

Number of times this article has been viewed

\author{
April N Naegeli' \\ Timothy E Stump ${ }^{2}$ \\ Risa P Hayes' \\ 'Global Health Outcomes, Eli Lilly \\ and Company, Indianapolis, IN, USA; \\ ${ }^{2}$ Consultant, Indianapolis, IN, USA
}

Correspondence: April N Naegeli Research Scientist, Global Health Outcomes, Eli Lilly and Company, Lilly Corporate Center, Drop Code 1833, Indianapolis, IN 46285, USA

Tel + I 3172760339

Fax+I 3174332997

Email naegelian@lilly.com
Objective: To explore the use of Diabetes Symptom Checklist-Revised (DSC-R) Cognitive Distress, Fatigue, Hyperglycemia, and Hypoglycemia subscales as measures of acute diabetesassociated symptoms in patients with both type 1 and 2 diabetes.

Research design and methods: Our study was conducted in context of two international, multicenter, randomized clinical trials for inhaled insulin. Confirmatory factor analyses and assessments of reliability and construct validity were performed.

Results: Study participants were 371 patients with type 2 (56\% male; mean age, 57 years) and 481 with type 1 diabetes ( $57 \%$ male, mean age, 40 years). In both populations a four-factor model was the best fit. Cronbach's $\alpha \geq 0.79$ and intraclass correlation coefficient $\geq 0.63$; subscales correlated $(P \leq 0.05)$ with measures of well-being and satisfaction $(0.12 \leq r \leq 0.71)$. In patients with type 1 diabetes, three subscales correlated $(P<0.05)$ with A1C.

Conclusions: The psychometric properties of the DSC-R Cognitive Distress, Fatigue, Hyperglycemia, and Hypoglycemia suggest they may be utilized in clinical trials as reliable and valid measures of acute symptoms of diabetes.

Keywords: Diabetes Symptom Checklist-Revised, DSC-R, type 1 diabetes, type 2 diabetes, psychometric validation

Symptoms associated with type 1 and type 2 diabetes include: frequent urination, excessive thirst, extreme hunger, unusual weight loss, increased fatigue, irritability, and blurry vision. ${ }^{1}$ These symptoms are indicators of fluctuating blood glucose levels; that is, hyperglycemia or hypoglycemia, which can lead to long term complications such as kidney or cardiovascular disease and nerve damage. ${ }^{1}$

The Diabetes Symptoms Checklist Revised (DSC-R) is the revised version of the Type 2 Diabetes Symptom Checklist (DSC). Both 34-item measures are designed specifically to assess the symptom burden of diabetes. ${ }^{2}$ The original version is structured to assess symptom burden by weighting the troublesomeness of symptoms by frequency whereas the revised version assesses the of symptoms by frequency asking responders to reply "yes" or "no" to symptom occurrence followed by a rating of symptom troublesomeness. The DSC and DSC-R have both been validated and used extensively in type 2 diabetes research to demonstrate relationships between diabetes treatment, symptom severity, and health-related quality of life. ${ }^{3-10}$

Clinical trials evaluating drug therapy for treating diabetes measure A1C, reflecting glycemic control over three months, as the primary endpoint. In the context of short dura- 
tion research (clinical trials), only the acute symptoms resulting from fluctuating blood sugars are expected to show immediate change during this time frame. Therefore, as a means to reduce respondent burden in clinical trials, we need to assess whether the 15 items of four DSC-R subscales (ie, Cognitive Distress, Fatigue, Hyperglycemia, and Hypoglycemia) focused on measuring only those acute diabetes-associated symptoms could be used as a reliable and valid measure to detect changes in those symptoms expected to change in response to initiation of antihyperglycemic treatment.

\section{Research design and methods}

This study was conducted in context of two international, multicenter, randomized clinical trials for an inhaled insulin. Study $1^{11}$ was conducted in insulin-naïve patients with type 2 diabetes who were poorly controlled by oral anti-hyperglycemic treatment. Participants of Study $2^{12}$ were patients with type 1 diabetes who were poorly controlled on their current insulin regimen.

These studies presented the opportunity to evaluate psychometric properties (factor structure, reliability, validity) of the Cognitive Distress (four items), Fatigue (four items), Hyperglycemia (four items), and Hypoglycemia (three items) subscales of the DSC-R as a measure of acute diabetes-associated symptoms. Both trials were conducted in agreement with the Declaration of Helsinki and the International Conference on Harmonization, Guidelines to Good Clinical Practice and participants signed an informed consent prior to participation.

Participants were administered the 15 items of the DSC-R at screening, baseline and six-month study visits. The DSC-R items ask respondents to recall the last four weeks and consider each symptom in terms of whether they experienced it and if so, how troublesome it was. A response "no" to the presence of a symptom equated to the item score 0 . Participants responding "yes" to the presence of a symptom were subsequently asked to indicate how troublesome the symptom was on a 5-point scale ranging from "not at all" = 1 to "extremely troublesome" $=5$. Subscale scores were calculated by summing item scores and dividing the sum by the number of items. Subscale scores range from 0 to 5 with higher scores corresponding to greater symptom severity.

Confirmatory factor analysis (CFA) was performed on baseline data. Parameter estimates were obtained for hypothesized three- and four-factor models. Goodness of fit was assessed with the chi-square test and with the fit indices of Comparative Fit Index (CFI), Root Mean Square Error of Approximation (RMSEA), and Standardized Root Mean Residual (SRMR). Maximum likelihood estimation was performed, for which a CFI $>0.95$, and SRMR $<0.08$ were considered indicators of a good fitting model. ${ }^{13}$

Additional psychometric evaluations: internal reliability at baseline using Cronbach's $\alpha$; test-retest reliability between screening and visit 2 (2 weeks) using intraclass correlation coefficient (ICC); responsiveness was calculated as the mean difference in scores from baseline to six months divided by standard deviation of baseline scores, compared to effect sizes of 0.2 (small), 0.5 (medium) and 0.8 (large); ${ }^{14}$ and Pearson correlations between DSC-R subscales and other patientreported outcomes (Well-Being Questionnaire-12,15 Diabetes Satisfaction Questionnaire ${ }^{16}$ ) and A1C at baseline.

\section{Results}

Participants who had complete responses for DSC-R items at baseline included 371 of 411 randomized patients with type 2 diabetes (56\% male, mean age $=57$ years, 62\% Caucasian) in Study 1, and 481 of 500 randomized patients with type 1 diabetes ( $57 \%$ male, mean age $=40$ years, $65 \%$ Caucasian $)$ in Study 2 (Table1).

Model fit statistics for study 1 indicated the DSC-R and original DSC hypothesized model (four-factor model with Cognitive Distress [four items], Fatigue [four items], Hyperglycemia [four items], and Hypoglycemia [three items]) fit the data adequately, although, modification indices showed that item 3 (sleepiness or drowsiness) improved model fit results by loading on the fatigue factor, rather than cognitive distress factor, with $\mathrm{CFI}=0.96$ and $\mathrm{SRMR}=0.038$. Factor loadings for all items were $\geq 0.62$. Goodness of model fit in the type 1 diabetes group was similar to the type 2 diabetes group with similar factor loadings evident across the groups. The internal reliability for the four subscales, as dictated by the CFA model, in both populations was $\geq 0.79$. Intraclass correlations were $\geq 0.62$ (Table 2). A hypothesized three-factor model combining cognitive distress and fatigue subscales into one psychological subscale (to reflect the original DSC structure ${ }^{2,3}$ ) was also investigated (results not shown). However, study data did not fit the model well.

Changes in A1c from baseline to 6 months were observed in Study 1 (mean difference $=-0.79 \%, P<0.001$ ),

Table I Characteristics of study participants

\begin{tabular}{lll}
\hline Patients & Study I $(\mathbf{N}=\mathbf{3 7 I})$ & Study 2 $(\mathbf{N}=\mathbf{4 8}$ I) \\
\cline { 2 - 3 } & Type 2 diabetes & Type I diabetes \\
\hline Mean Age (Years) & 57 & 40 \\
Male (\%) & 56 & 57 \\
Caucasian (\%) & 62 & 65 \\
$\mathrm{HbA}_{\mathrm{Ic}}$ at screening & $8.2 \pm 1.1 \%$ & $7.9 \pm 1.2 \%$ \\
\hline
\end{tabular}

Abbreviation: $\mathrm{HbA}_{\mathrm{lc}}$, glycosylated hemoglobin. 
Table 2 Reliability, statistics, and Pearson correlations for DSC-R subscales: cognitive distress, fatigue, hyperglycemia and hypoglycemia

\begin{tabular}{|c|c|c|c|c|c|c|c|c|c|}
\hline & & \multicolumn{4}{|c|}{$\begin{array}{l}\text { Study I } \\
\text { Patients with type } 2 \\
\text { diabetes } N=37 \text { I }\end{array}$} & \multicolumn{4}{|c|}{$\begin{array}{l}\text { Study } 2 \\
\text { Patients with type I } \\
\text { diabetes } N=48 \mathrm{I}\end{array}$} \\
\hline & & $\begin{array}{l}\text { Cognitive } \\
\text { distress }\end{array}$ & Fatigue & $\begin{array}{l}\text { Hyper- } \\
\text { glycemia }\end{array}$ & $\begin{array}{l}\text { Hypo- } \\
\text { glycemia }\end{array}$ & $\begin{array}{l}\text { Cognitive } \\
\text { distress }\end{array}$ & Fatigue & $\begin{array}{l}\text { Hyper- } \\
\text { glycemia }\end{array}$ & $\begin{array}{l}\text { Hypo- } \\
\text { glycemia }\end{array}$ \\
\hline \multirow{2}{*}{$\begin{array}{l}\text { Reliability } \\
\text { statistics }\end{array}$} & $\mathrm{ICC}^{\mathrm{a}}$ & 0.76 & 0.72 & 0.68 & 0.73 & 0.72 & 0.74 & 0.62 & 0.66 \\
\hline & Crohnbach's $\alpha$ & 0.91 & 0.91 & 0.81 & 0.83 & 0.90 & 0.87 & 0.82 & 0.79 \\
\hline \multirow{5}{*}{$\begin{array}{l}\text { Pearson } \\
\text { correlations }\end{array}$} & AIC & 0.08 & 0.07 & $0.13^{d}$ & 0.04 & 0.07 & $0.1 \mathrm{I}^{\mathrm{d}}$ & $0.14^{e}$ & $0.12^{\mathrm{d}}$ \\
\hline & Positive well-being ${ }^{\mathrm{b}}$ & $-0.32^{\mathrm{e}}$ & $-0.39^{e}$ & $-0.14^{\mathrm{e}}$ & $-0.31^{\mathrm{e}}$ & $-0.37^{e}$ & $-0.38^{e}$ & $-0.15^{\mathrm{e}}$ & $-0.33^{e}$ \\
\hline & Negative well-being ${ }^{\mathrm{b}}$ & $0.59^{e}$ & $0.58^{\mathrm{e}}$ & $0.32^{\mathrm{e}}$ & $0.59^{e}$ & $0.47^{\mathrm{e}}$ & $0.46^{\mathrm{e}}$ & $0.29^{e}$ & $0.50^{\mathrm{e}}$ \\
\hline & Energy $^{\mathrm{b}}$ & $-0.54^{\mathrm{e}}$ & $-0.7 I^{\mathrm{e}}$ & $-0.32^{\mathrm{e}}$ & $-0.52^{\mathrm{e}}$ & $-0.40^{\mathrm{e}}$ & $-0.61^{e}$ & $-0.24^{\mathrm{e}}$ & $-0.39^{e}$ \\
\hline & Satisfaction $^{c}$ & $-0.24^{e}$ & $-0.33^{e}$ & $-0.12^{\mathrm{d}}$ & $-0.30^{e}$ & $-0.17^{e}$ & $-0.21^{\mathrm{e}}$ & -0.09 & $-0.16^{e}$ \\
\hline
\end{tabular}

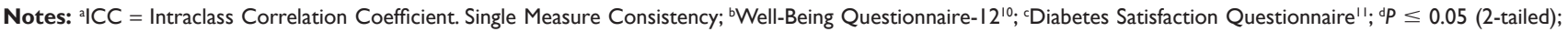
eP $\leq 0.0$ I (2-tailed).

responsiveness of DSC-R subscales was demonstrated, mean change in score and effect size: Cognitive Distress, -0.1 $(P=0.06), 0.1$; Fatigue, $-0.05(P=0.36), 0.04$; Hyperglycemia, $-0.18(P=0.001), 0.2$, Hypoglycemia, $-0.1(P=0.07)$, 0.1 . No changes in A1c were observed in Study 2, therefore, responsiveness was not calculated. Significant relationships $(P \leq 0.05)$ found in the hypothesized direction between the 4 DSC-R subscales and well-being and treatment satisfaction components $(0.12 \leq r \leq 0.71)$, suggest construct validity. Significant, although weak, correlations $(P \leq 0.05)$ with A1C were identified for three subscales among the type 1 diabetes group $(0.12 \leq r \leq 0.14)$ (Table 2$)$.

\section{Conclusions}

The objective of this study was to explore the use of DSC-R Cognitive Distress, Fatigue, Hyperglycemia, and Hypoglycemia subscales as measures of acute diabetes-associated symptoms in patients with type 1 and 2 diabetes. This study suggests that the four subscales, with a modified four-factor structure, rather than the three-factor structure linking the cognitive distress and fatigue subscales as in the original and revised DSC, ${ }^{2,3}$ could be utilized as a robust 15-item acute diabetes-associated symptom measure.

As demonstrated by previous research utilizing the full DSC-R, evidence from this study also substantiates models hypothesizing associations between perceived consequences of antihyperglycemic treatment with patient's well-being ${ }^{5,6}$ as well as being one of many drivers of treatment satisfaction. ${ }^{17,18}$ As patients perceive symptom severity to decrease the better they perceive their well-being or general health which in turn results in higher satisfaction in treatment. Patients with type 2 diabetes tend to report the occurrence of symptoms associated with high blood glucose over any other symptom, regardless of A 1c level, ${ }^{19}$ which supports responsiveness to change over time detected only by the hyperglycemia subscale.

The lack of or low correlation between A1C and symptoms may be attributed to differences in measurement periods as A1C reflects a three-month period of blood glucose levels while the DSC-R asks patients to recall and average diabetes symptoms over the past four weeks. ${ }^{18}$ This suggests that $\mathrm{A} 1 \mathrm{C}$ may not be the most sensitive clinical measure to reflect changes in patient symptoms in clinical trial research. The more appropriate measures for clinical trials to monitor changes in acute symptoms of diabetes over time may be fasting blood glucose in addition to the 15-item DSC-R with a shortened recall period.

Results of this study represent patients enrolled in a clinical trial and may not necessarily be representative of all patients with diabetes. Further research evaluating sensitivity to change over time, or responsiveness, involving the Cognitive Distress, Fatigue, Hyperglycemia, and Hypoglycemia subscales of the DSC-R is recommended. However, as a means to reduce respondent burden in clinical trials, this study suggests that this 15 -item measure is reliable and valid in assessing relevant acute symptoms for patients with type 1 and type 2 diabetes.

\section{Acknowledgments}

This study was funded by Eli Lilly and Company and is related to NCT00325364 and NCT00356109, ClinicalTrials.gov.

\section{Disclosures}

Drs. Naegeli and Hayes are fulltime employees and stockholders of Eli Lilly and Company. Eli Lilly and 
Company develops and markets products for the treatment of diabetes.

\section{References}

1. American Diabetes Association. Available from: http://www.diabetes. org/ Accessed on January 10, 2010.

2. Grootenhuis PA, Snoek FJ, Heine RJ, Bouter LM. Development of a type 2 diabetes symptom checklist: a measure of symptom severity. Diabet Med. 1994;11:253-261.

3. Arbuckle RA, Humphrey L, Vardeva K, et al. Psychometric evaluation of the Diabetes Symptom Checklist-Revised (DSC-R) - A measure of symptom distress. Value Health. 2009;12(8):1168-1175.

4. Gulliford MC, Mahabir D. Relationship of health-related quality of life to symptom severity in diabetes mellitus: a study in Trinidad and Tobago. J Clin Epidemiol. 1999;52(8):773-780.

5. Adriaanse MC, Dekker JM, Spijkerman AMW, et al. Healthrelated quality of life in the first year following diagnosis of type 2 diabetes: newly diagnosed patients in general practice compared with screening-detected patients: the Hoorn Screening Study. Diabet Med. 2004;21:1075-1081.

6. Adriaanse MC, Dekker JM, Spijkerman AMW, et al. Diabetes-related symptoms and negative mood in participants of a targeted populationscreening program for type 2 diabetes: The Hoorn Screening study. Qual Life Res. 2005;14:1501-1509.

7. de Sonnaville JJJ, Snoek FJ, Colly LP, Deville W, Wijkel D, Heine RJ. Well-being and symptoms in relation to insulin therapy in type 2 diabetes. Diabetes Care. 1998;21(6):919-924.

8. Van der Does FEE, de Neeling JND, Snoek FJ. Symptoms and wellbeing in relation to glycemic control in type II diabetes. Diabetes Care. 1996;19:204-210.

9. Van der Does FEE, de Neeling JND, Snoek F. Randomized study of two different target levels of glycemic control within the acceptable range in type 2 diabetes: effects on well-being at 1 year. Diabetes Care. 1998;21(12):2085-2093.
10. Vinik AI, Dailey G, Zhang Q. Insulin glargine (GLAR) improves health related quality of life (HRQOL) in patients with Type 2 Diabetes (T2DM) inadequately controlled on sulfonylurea plus metformin (SU+MET) (Abstract). Diabetes. 2005;54(Suppl 1):A142.

11. Gross JL, Nakano M, Colon-Vega G, et al. Initiation of prandial insulin therapy with AIR inhaled insulin or insulin lispro in patients with Type 2 diabetes: a randomized noninferiority trial. Diabetes Technol Ther. 2009;11(2):S27-S34.

12. Comulada AL, Renard E, Nakano M, et al. Efficacy and safety of AIR inhaled insulin compared to insulin lispro in patients with type 1 diabetes mellitus in a 6-month, randomized, noninferiority trial. Diabetes Technol Ther. 2009;11(2):S17-S25.

13. Hu L, Bentler PM. Cutoff criteria for fit indexes in covariance structure analysis: conventional criteria versus new alternatives. Structural Equation Modeling. 1999;6(1):1-55.

14. Cohen J. Statistical Power Analysis for the Behavioral Sciences. New York, NY: Academic Press; 1988.

15. Bradley C. The diabetes treatment satisfaction questionnaire. In: Bradley C, editor. Handbook of Psychology and Diabetes: A guide to psychological measurement in diabetes research and practice. Chur, Switzerland: Harwood Academic Publishers; 1994, p. 111-132.

16. Bradley C. The 12-Item Well-Being Questionnaire: origins, current stage of development, and availability. Diabetes Care. 2000;23:875.

17. Peyrot M, Rubin RR. How does treatment satisfaction work? Modeling determinants of treatment satisfaction and preference. Diabetes Care. 2009;32(8):1411-1417.

18. Hayes RP, Bowman L, Monahan PO, Marrero DG, McHorney CA. Understanding diabetes medications from the perspective of patients with Type 2 diabetes: prerequisite to medication concordance. Diabetes Educ. 2006;32(3):404-414.

19. Hayes RP, Muchmore DB. Patients with Type 2 diabetes on oral antidiabetic therapy report similar treatment satisfaction, well-being, and symptom burden regardless of degree of glycemic control [Abstract]. Diabetes. 2008:A1385.

\section{Publish your work in this journal}

Diabetes, Metabolic Syndrome and Obesity: Targets and Therapy is an international, peer-reviewed open-access journal committed to the rapid publication of the latest laboratory and clinical findings in the fields of diabetes, metabolic syndrome and obesity research. Original research, review, case reports, hypothesis formation, expert opinion and commentaries are all considered for publication. The manuscript management system is completely online and includes a very quick and fair peer-review system, which is all easy to use. Visit $\mathrm{http}: / / \mathrm{ww} w$. dovepress.com/testimonials.php to read real quotes from published authors. 